EESTI NSV TEADUSTE AKADEEMIA TOIMETISED 1954. III kd., nr. 2 ИЗВЕСТИЯ АКАДЕМИИ НАУК ЭСТОНСКОЙ ССР 1954. Том III, № 2

\title{
К ВОПРОСУ ОБ УМЕНЬШЕНИИ РАСХОДА КОКСА ПРИ ПЛАВКЕ ЧУГУНА В ВАГРАНКЕ
}

\author{
А. Г. Кимм
}

Вагранка, прототип которой был впервые построен в России еще в 1774 году, является и в настоящее время самым экономичным и распространенным агрегатом для плавки чугуна в литейных цехах.

Преимуществами вагранки по сравнению с другими плавильными печами являются простота ее конструкции и быстрота плавления, обусловленная противоточностью движения вниз холодной шихты и поднятия вверх, навстречу шихте, потока горячих газов. При этом чугун расплавляется на определенной высоте в шахте вагранки, и капли жидкого чугуна, проходя через слой раскаленных кусков кокса, нагреваются до определенной температуры.

Этот, на первый взгляд простой, плавильный процесс до настоящего времени недостаточно изучен, и теория ваграночной плавки еще нуждается в дальнейшей серьезной разработке.

До недавнего прошлого большинство вагранок имело для подачи воздуха один горизонтальный ряд фурм с большими и расширяющимися выходными сечениями с целью уменьшения сопротивления движению воздуха, подаваемого под небольшим давлением, в 300-1000 мм вод. ст.

В последние два десятилетия сравнительно быстрое распространение получили вагранки с двумя и тремя рядами фурм, дающие в ряде случаев лучшие результаты, чем вагранки с одним рядом фурм.

Для обоснования целесообразности перехода от однорядных вагранок к многорядным были предложены различные теории. Однако нужно отметить, что имеющиеся теоретические представления далеко не объясняют известные в настоящее время факты и что технико-экономические показатели работы многих современных многорядных вагранок являются весьма невысокими.

Для расплавления и перегрева 100 кг чугуна до $1400^{\circ}$ достаточно 29000 ккал. Это количество тепла может быть получено при полном сгорании 4,5 кг кокса, содрежащего $85 \%$ углерода. Однако в действительности в современных вагранках кокса расходуется в три-четыре раза больше. Это показывает, что вопрос повышения экономичности работы вагранок и интенсификации процессов горения и плавления в них является весьма актујальным.

Не умаляя значения серьезной работы, проделанной участниками двух последних общесоюзных конференций, состоявшихся в 1950 и 1953 годах, все же нужно отметить, что ряд основных вопросов остался 
нерешенным, так как и в настоящее время вагранки имеют большие потери тепла с отходящими газами и отравляют атмосферу цеха и окружающего района окисью углерода.

Ниже сделана попытка критически рассмотреть имеющиеся данные по теории и практике применения вагранок с многорядными фурмами. Можно смело утверждать, что устройство фурм имеет решающее значение для работы вагранки, так как способ подачи воздуха определяет процессы горения, а следовательно и теплообмен в вагранке.

Для того чтобы правильно конструировать вагранки с многорядными фурмами, необходимо прежде всего решить некоторые основные вопросы, такие как назначение дополнительных фурм, их целесообразные размеры и расположение.

Однако некоторые исследователи подходят к этим вопросам весьма упрощенно. Так, проф. Л. М. Мариенбах $\left({ }^{4}\right)$, установив наблюдениями, что в продуктах горения у однорядных вагранок содержится в среднем $12 \% \mathrm{CO}_{2}$ и $15 \% \mathrm{CO}$, а у многорядных $-18 \% \mathrm{CO}_{2}$ и $5 \% \mathrm{CO}$, делает на основании этого вывод, что роль дополнительных рядов фурм заключается в дожигании окиси углерода. Подсчитав, что расход воздуха на 1 кг топлива в первом случае составляет $1,44 \mathrm{~m}^{3}$, а во втором $1,78 \mathrm{~m}^{3}$, он утверждает, что дополнительные ряды фурм должны дать воздуха $1,78 \frac{1,44}{1,44}=24 \%$ и, следовательно, их сечение должно быть $\frac{24}{124} \simeq 20 \%$ 。 от общей площади фурм. Дальше Л. М. Мариенбах допускает, что $10-20 \%$ этого воздуха расходуется на окисление твердого топлива, и поэтому увеличивает сечение еще на $5 \%$. Исходя из этих расчетов, он рекомендует принимать площадь дополнительных фурм в $25 \%$ от общей площади всех фурм. Площадь всех фурм принимается в настоящее время равной $25 \%$ от площади сечения вагранки. Однако некоторые авторы, например Л. Я. Садогурский $\left({ }^{7}\right)$, считали нужным увеличить общую площадь фурм до $35 \%$. Вместе с тем следует отметить, что инж. Е. Е. Эренбург еще в 1943 году на основании своих опытов считал нужным площадь дополнительных рядов фурм принимать равной $40-60 \%$ от площади основных фурм. Но Л. М. Мариенбах в своей статье $\left({ }^{4}\right)$ резко критикует инж. Әренбурга, указывая на то, что было бы грубой ошибкой принять его предложения. Қак известно, в дальнейшем положения Л. М. Мариенбаха были взяты в основу для расчета типовых вагранок Гипромеза $\left({ }^{9}\right)$ и приведены в качестве нормативных в справочнике по машиностроению $\left({ }^{10}\right)$.

О том, что конструкции современных вагранок являются далеко не совершенными и что они должны быть коренным образом пересмотрены, евидетельствует ряд фактов.

П. П. Берг и Л. И. Серебриер ('), анализируя результаты работы многорядных вагранок, указывают на то, что в ряде случаев устройство многорядных фурм не принесло заметного улучшения по сравнению с работой обычных, однорядных вагранок. В своей статье они делают существенное замечание относительно того, что воздух, поступающий в вагранку через дополнительные ряды фурм, не только дожигает часть СО в $\mathrm{CO}_{2}$, но и с жигает ч астькокса, в результате чегосозд ю тся дополнительные очаги горения. Они приводят некоторые данные о размерах площади дополнительных рядов фурм, указывая, что увеличение их площади в пределах от $\frac{1}{8}$ до $\frac{2}{3}$ общей площади основных фурм привело к прогрессивному увеличению производительности вагранки. Известно также, что крупные вагранки работают до сих пор с одним рядом фурм. В работе Л. М. Мариенбаха и Ю. С. Сухарчука (5) 
приведены результаты исследования процессов горения в опытной вагранке, которые указывают на то, что на высоте до 350 мм над фурмами совершенно не обнаружено окиси углерода. Но ведь по теории Л. М. Мариенбаха основной задачей дополнительных рядов фурм является дожигание окиси углерода. Возникает вопрос: как же можно дожигать окись углерода, если ее в этой зоне вагранки нет?

Имеются и другие серьезные факты, которые указывают на необходимость пересмотра принципов конструкции многорядных вагранок. Однако Л. М. Мариенбах, не меняя своих рекомендаций по интенсификации ваграночного процесса, вместо того чтобы исправить конструктивные недостатки вагранок, делает необоснованное предложение $\left({ }^{6,8}\right)$ давать возможно больше воздуха (в пределах $140-160 \mathrm{~m}^{3} / \mathrm{m}^{2}$ мин) с увеличением расхода кокса до $11-13 \%$.

Некоторые последователи Л. М. Мариенбаха, желающие улучшить ваграночный процесс за счет дальнейшего увеличения количества воздуха, называют еще более крупные цифры. На Харьковской конференции литейщиков в 1953 году Б. А. Носков в своем докладе предлагал увеличить количество воздуха до $200 \mathrm{~m}^{3} / \mathrm{M}^{2}$ мин.

В связи с этим мы вынуждены напомнить, что вагранки при избыточном количестве воздуха работать не могут. Покажем на примере, к чему может привести работа с повышенным расходом воздуха.

Пусть средние содержания в ваграночном газе $\mathrm{CO}_{2}$ и $\mathrm{CO}$ относятся как $80: 20$ (наилучший случай); тогда для' сжигания 1 кг кокса (при содержании $81 \%$ углерода) требуется $6,5 \mathrm{~m}^{3}$ воздуха. Если принять, по предложению Л. М. Мариенбаха, количество воздуха в $160 \mathrm{~m}^{3} / \mathrm{m}^{2}$ мин, то интенсивность сгорания кокса будет $\frac{160}{6,5}=24,7 \mathrm{kr} / \mathrm{m}^{2}$ мин. Принимая расход кокса в 10\% от расхода металла, получим удельную производительность вагранки равной 14,7 т/м²час, что значительно превышает практически достигаемую производительность $(9-9,5$ т/м² час).

При таком большом расходе воздуха можно ожидать, что расход кокса в действительности возрастет на $15 \%$ и более.

Критическое рассмотрение имеющихся материалов по вопросам работы современных -многорядных вагранок приводит к выводу о необходимости серьезного и тщательного изучения влияния устройства фурм на показатели работы вагранок.

Ниже приведены краткие результаты исследований, проведенных нами в этом направлении.

\section{Методика работы}

Работа выполнялась на заводских вагранках в порядке оказания чугунно-литейным цехам таллинских заводов технической помощи в налаживании рабочих процессов плавки чугуна в вагранках. Основной задачей работы было нахождение способов уменьшения расхода кокса без понижения качества литья.

С начала 1951 года работы производились на Таллинском машиностроительном заводе, работники которого пытались понизить расход кокса путем частичной замены его горючим сланцем. Работа выполнялась сотрудниками Института энергетики Академии наук ӘССР совместно с коллективом литейщиков завода имени Карла Маркса (Ленинград) при участии научных работников А. Н. Соколова и К. М. Скобникова. В результате длительной совместной работы была установлена производственная возможность применения сланца при плавке чугуна. Главным же до- 
стижением в работе было то, что удалось установить на практике ряд недостатков у существующих многорядных вагранок и наметить пути их устранения. Коллектив ленинградских литейщиков в основном обратил внимание на улучшение плавильного процесса посредством уменьшения диаметра нижней части вагранки по сравнению с диаметром ее шахты, а коллектив таллинских литейщиков - на размеры и расположение фурм.

Совместный обмен опытом и ценное руководство со стороны А. Н. Соколова позволили Таллинскому машиностроительному заводу (ТMЗ), после проведения указанной работы и ряда конструктивных изменений в вагранке, перейти на новый режим работы, при котором, вместо обычного расхода рабочего кокса в $13 \%$, вагранка стала работать уже во второй половине 1951 года с 6-7\% рабочего кокса.

В 1952 году Институт энергетики Академии наук Эстонской ССР заключил дополнительные договоры о технической помощи еще с двумя таллинскими заводами с целью внедрения результатов работы 1951 года на других заводах, а также для продолжения исследований *.

За истекшие два года нами было исследовано на трех заводах более 65 производственных плавок, сделано около 1000 газовых анализов и несколько десятков анализов исходных шихтовых материалов и кокса; кроме того, были проведены механические испытания и анализы полученного чугуна.

Основные опыты, выполненные нами на ТМЗ, проводились на трехрядной вагранке с внутренним диаметром 0,8 м и высотой от лещади до загрузочного окна 5,87 м, имеющей механическую боковую завалку и копильник. Расположение фурм и размеры этой вагранки указаны на фиг. 1. В кожухе вагранки, начиная с высоты 500 мм над фурмами, было высверлено девять отверстий диаметром 40 мм, располөженных вдоль образующей вагранки по всей ее высоте. Через эти отверстия брались каждые 20-30 мин. пробы газа для анализа и вводились термопары для измерения температур.

Дальнейшие исследования проводились еще на трех других вагранках различной конструкции, работающих на Таллинском машиностронтельном заводе, Заводе торгового оборудования (ЗТО) и заводе «Пионер». Следует отметить, что вагранка 3 ТО являлась типовой вагранкой, выполненной в соответствии с данными Гипромеза и вступившей в работу в 1951 году. При исследовании на всех заводах изучались рабочие процессы без изменения способов подготовки шихты и других местных заводских условий. Вследствие этого, как правило, плавки велись с загрузкой в вагранку целых чушек чугуна, без разбивки их на части, как этого требуют нормальные условия работы. Лом чугуна применялся различный, от самых мелких до очень крупных кусков, которые по весу доститали $50-60$ кг и больше. Единственно, что при этом пытались сохранить, - это одинаковые условия проведения однотипных опытов.

Температуру жидкого чугуна при каждом выпуске из копильника измеряли на жолобе проверенным оптическим пирометром (с нитью накаливания); все значения температуры приводились без введения поправки на абсолютно черное тело.

Состав газов определялся с помощью газоанализатора ВТИ или прибора Орса. Отбор газа производился водоохлаждаемыми трубками.

Количество воздуха определялось двумя способами. На опытной вагранке ТМЗ в начальный период опытов (в 1951 году) мы выполняли

* В проведении данных исследований, помимо автора статьи, принимал участие младший научный сотрудник Института энергетнки АН ЭССР Э. Вейгель. 


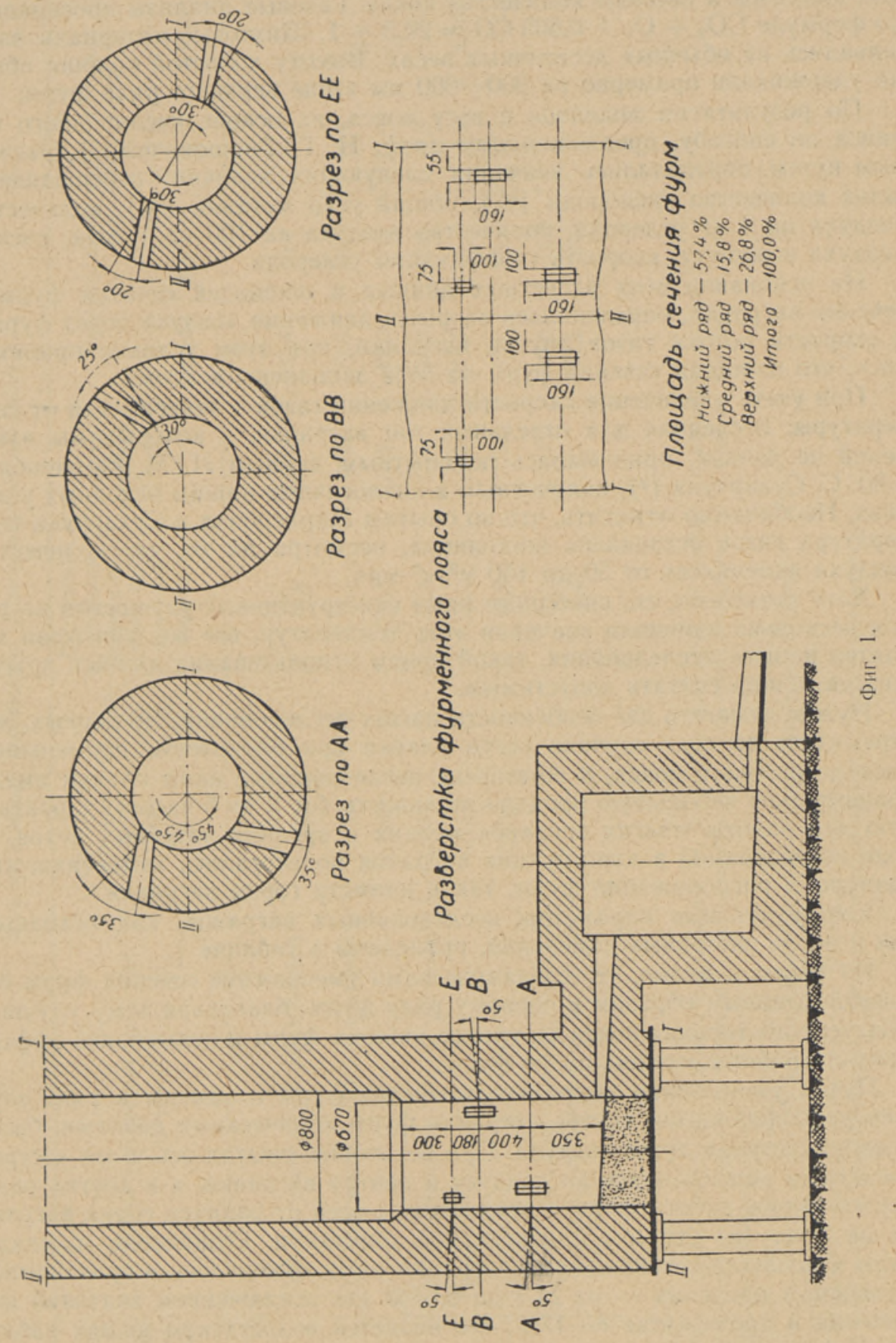


измерения шайбой. Однако после проведенных расчетов было обнаружено, что имеется утечка воздуха порядка $10-15 \%$ вследствие неплотности в фурменных заглушках. В дальнейшем мы подсчитывали количество воздуха по кислородному балансу, принимая за основу данные газовых анализов и весовые количества кокса. Газовые анализы проверялись по формуле $\mathrm{CO}_{2}+\mathrm{O}_{2}+0,605 \mathrm{CO}=20,5+1$. Шихтовые материалы взвешивались на обычных десятичных весах. Высоту холостой колоши обычно удерживали примерно на 500-600 мм выше верхнего ряда фурм.

По результатам анализов и весу кокса, на основе кислородного баланса по способу, предложенному проф. Н. Г. Гиршовичем $\left({ }^{2}\right)$, расчетным путем определялись значения следующих величин: перешедшее в шлак количество кислорода (\%), общий угар металла (\%), количество воздуха на 1 кг углерода, количество воздуха на 100 кг чугуна, расход воздуха в минуту, скорость газификации углерода.

На основании этих расчетных данных и площадей сечения фурм и сечения вагранки, определялась скорость движения воздуха через фурмы и скорость потока газов внутри вагранки; при этом условно принималось, что площади сечения фурм на $50 \%$ заполнены коксом.

При учете увеличения скорости движения газов в зависимости от температуры, последняя для отдельных зон вагранки, в которых мы измерений не делали, принималась по опытным данным Л. М. Мариенбаха и Ю. С. Сухарчука (6), полученным в аналогичных нашим исходных условиях. Необходимо отметить, что по опытам Мариенбаха и Сухарчука температура газов оставалась постоянной, несмотря на то, что количество воздуха изменялось от 50 до $150 \mathrm{~m}^{3} / \mathrm{M}^{2}$ мин.

Хотя возможно, что внесенные нами конструктивные улучшения вагранок несколько изменили значения этих температур, все же, учитывая характер нашего исследования, такой прием использования данных других опытов можно считать допустимым.

Нужно отметить две особенности наших исследований. Во-первых, мы стремились во всех случаях вести плавки при возможном наименьшем расходе рабочего кокса, а во-вторых, исследованные нами плавки имели сравнительно небольшую продолжительность (от 3 до 5 часов), характерную для работы многих вагранок мелких и средних литейных цехов. В ходе исследований в конструкции вагранок подвергались изменению как размеры и расположение фурм, так и диаметр горна вагранки.

Конструктивные параметры исследованных вагранок, как исходные, так и после внесенных изменений, приведены в таблице 1.

Из таблицы видно, что сделанное нами уменьшение сечения фурм относится главным образом к первому ряду фурм, благодаря чему улучшились условия горения кокса на уровне нижних фурм и повысилась эффективность работы верхних рядов фурм.

Путем уменьшения выходных отверстий фурм и.замены в ряде случаев расширяющихся внутрь вагранки фурм коническими соплами, было создано «острое» дутье воздуха. При некоторых опытах ось этого «острого» потока направлялась по радиусу к центру вагранки, а в других опытах изучалась работа фурм с отклонением осей от радиуса горна вагранки на угол $15-20^{\circ}$ в горизонтальной плоскости. Отношение площади фурм к площади сечения горна вагранки нами изменялось в практически возможных пределах - от 24,7 до $6,65 \%$ (за исключением значений отношения в промежутке $8-13 \%$, что является недостатком наших работ так как это не дало возможности выяснить зависимости, определяющие выбор наивыгоднейших соотношений между площадью фурм и площадью внутреннего сечения вагранки). 


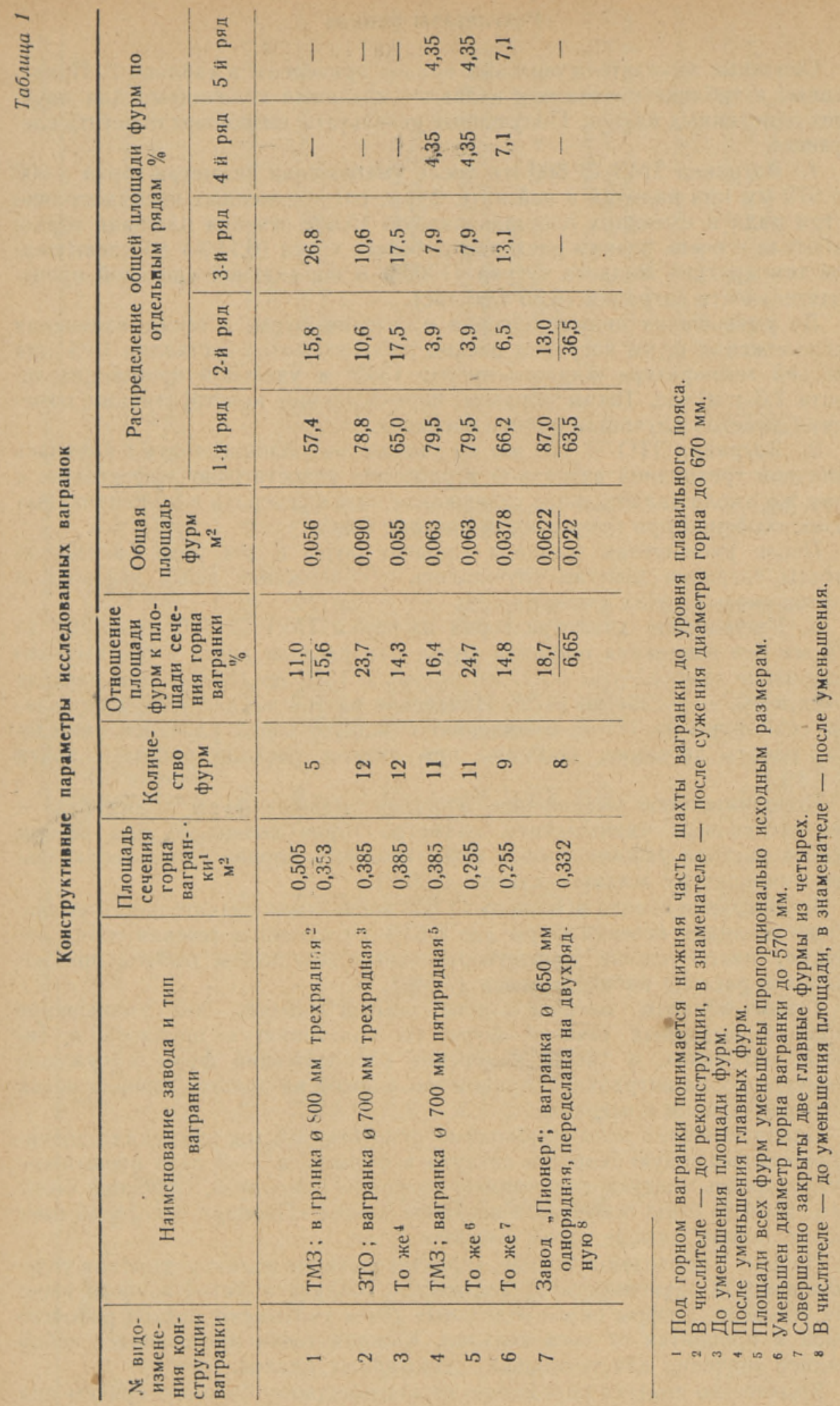




\section{Результаты опытов}

Основные показатели опытных плавок приведены в таблице 2. Приведенные в таблице показатели являются средними величинами для двухтрех однотипных плавок. Полученные результаты позволяют отметить следующее.

1. Вагранка ТМЗ $\varnothing 800$ мм после уменьшения диаметра горна с 800 до 670 мм при наличии в ней пяти фурм, расположенных несимметрично в три ряда и имеющих площадь равную $15,6 \%$ сечения площади горна, работала с очень низким расходом рабочего кокса $(6,11 \%)$ при повышенной температуре жидкого чугуна $\left(1365^{\circ}\right)$ и нормальной удельной произ-

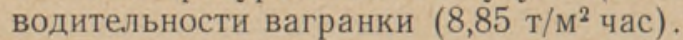

До уменьшения диаметра горна и сечения фурм, а также изменения расположения фурм вагранки расход рабочего кокса составлял $13 \%$ при средней температуре жидкого чугуна $1340^{\circ}$ и удельной производительности 7,6 т/м $\mathrm{m}^{2}$ час. Таким образом, перечисленные конструктивные изменения заметно улучшили работу вагранки.

2. Вагранка 3 ТО $\varnothing 700$ мм до уменьшения площади фурм являлась типичной трехрядной вагранкой и работала недостаточно эффективно, к тому же имела значительное содержание окиси углерода в колошниковых газах, особенно при повышенном расходе кокса.

После уменьшения площади главных фурм в два раза показатели работы вагранки заметно улучшились и содержание окиси углерода в колошниковых газах уменьшилось.

3. Уменьшение диаметра горна вагранки ТМЗ 700 мм с 700 до 570 мм без изменения площади фурм, при расходе кокса в 8\% вызвало повышение температуры жидкого чугуна с 1320 до $1345^{\circ}$ и при расходе кокса в $9 \%$ - с 1364 до $1372^{\circ}$. Изменение на той же вагранке направления осей фурм на $17^{\circ}$ по отношению к радиусу горна улучшило показатели работы вагранки, особенно при низком расходе рабочего кокса $(7-8 \%)$.

Дополнительное уменьшение площади главных фурм в два раза с соответственным уменьшением диаметра горна позволило при весьма низком расходе рабочего кокса $(7 \%)$ получить вполне удовлетворительную температуру жидкого чугуна $\left(1360^{\circ}\right)$.

4. Вагранка завода «Пионер» $\varnothing 650$ после очень значительного уменьшения площади сечения фурм (до $6,63 \%$ от площади сечения горна вагранки) имела вполне удовлетворительные результаты работы при небольшом расходе рабочего кокса $(7,5 \%)$.

Таким образом, из результатов опытов следует, что уменьшение площади выходных сечений фурм по сравнению с принятой в типовых вагранках, а также изменение расположения фурм и сужение диаметра горна вагранки благоприятно влияют на процесс горения кокса и процесс плавки в вагранке.

Одновременно с этим необходимо отметить, что мы применили значительно повышенную скорость воздуха в фурмах, в 2-3 раза превышающую скорость воздуха для типовой вагранки Гипромеза. Особенно большая скорость была получена в вагранке завода «Пионер», в которой имелось в полном смысле слова «острое» дутье.

На фиг. 2 приведены данные, характеризующие полноту сгорания углерода кокса в зависимости от количества воздуха и интенсивности горения углерода. Цифры около отдельных точек указывают расход рабочего кокса в процентах от веса завалки. Каждая точка представляет собой среднее значение для нескольких однотипных плавок.

Количество воздуха определено по кислородному балансу, причем для 


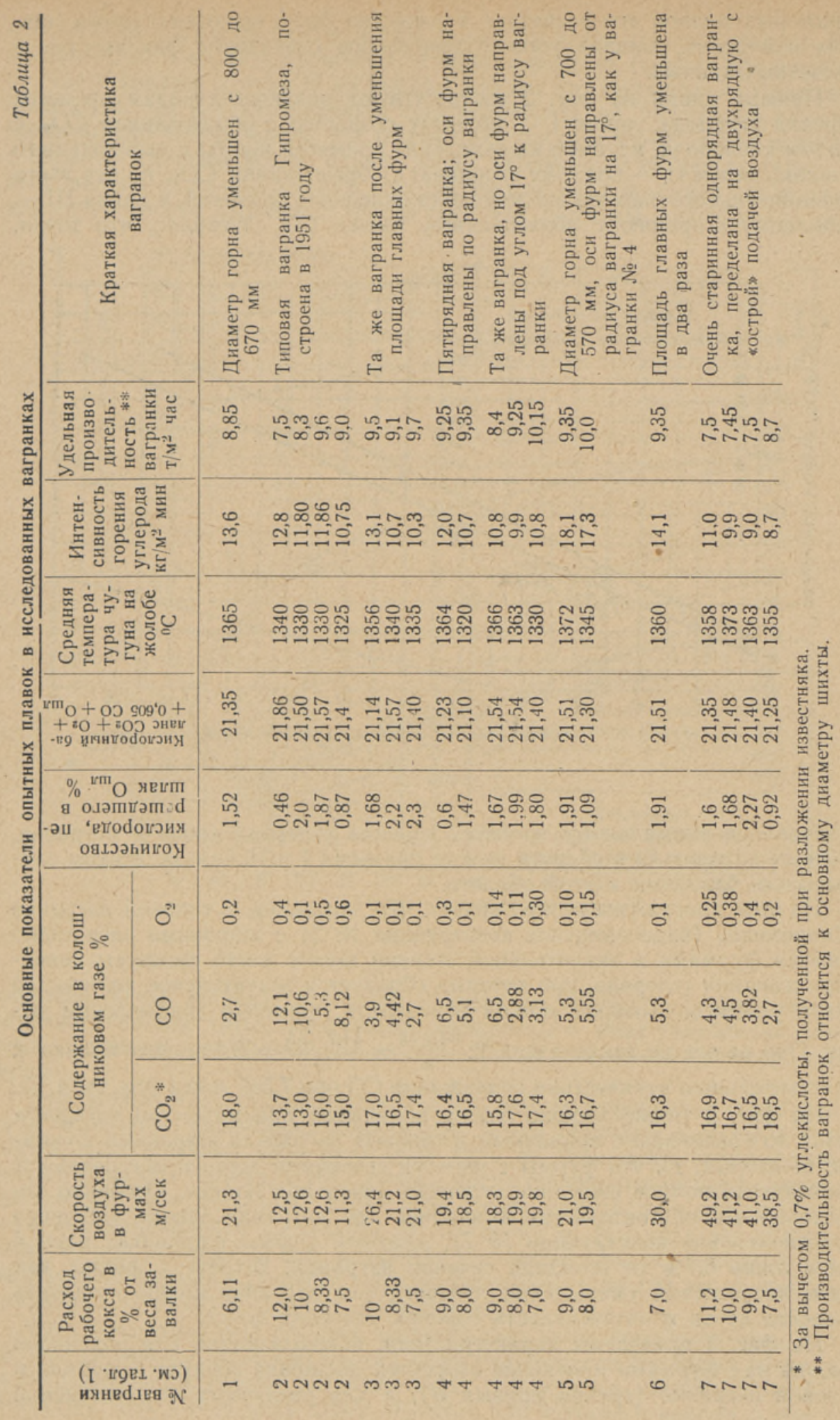


некоторых плавок это расчетное количество было проверено путем прямых измерений, давших удовлетворительное совпадение фактических и расчетных данных.

Прямые линии на фиг. 2 соответствуют различным видам процесса горения углерода: линия I - полному сгоранию с образованием $\mathrm{CO}_{2}$, с учетом кислорода, идущего на окисление примесей шихты и переходящего в шлак; линия II - полному сгоранию с образованием $\mathrm{CO}_{2}$, но без учета дополнительного расхода кислорода на окисление примесей, и линия III неполному сгоранию с образованием только СО. Очевидно, что точки,

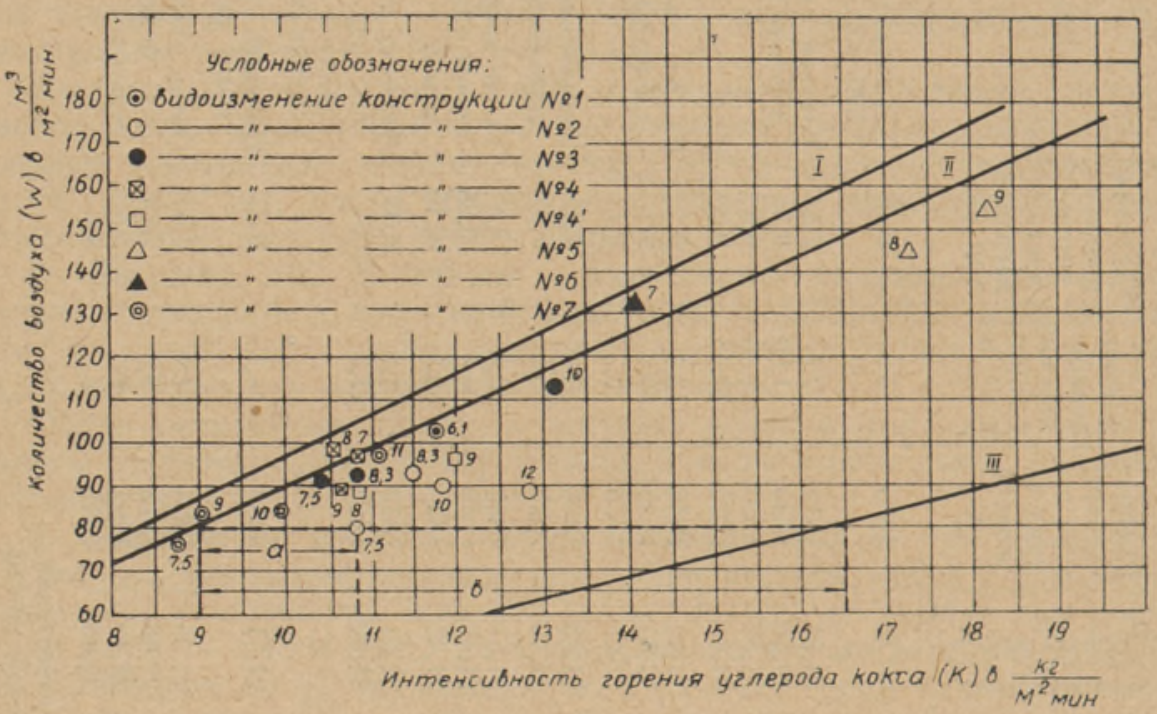

Фиг. 2.

отвечающие нормальному процессу горения углерода кокса в вагранке, должны находиться в области между прямыми I и II или, во всяком случае, быть близкими к этой области.

Из этой диаграммы можно видеть, что, например, в типовой вагранке «Гипромеза» (видоизменение конструкции № 2) с широкими расширяющимися фурмами в значительной степени имеют место процессы неполного сгорания углерода, при которых образуется значительное количество окиси углерода, которое можно определить примерно графическим путем. Оно равно, по данным фиг. $2: \frac{34,7 \cdot a}{\mathrm{~s}}=\frac{34,7 \cdot 3,5}{15}=8,1 \%$, что близко к действительным количествам содержания СО при 7,5\% кокса (см. табл. 2).

На фиг. 2 также хорошо видно, во-первых, преимущество «острого» дутья по сравнению с принятыми в типовых вагранках широкими фурмами, во-вторых, то, что фурмы с малыми сечениями хорошо обеспечивают практически полное сжигание углерода кокса при плавке. Особенно характерно эти обстоятельства выявились для вагранки завода «Пионер» (видоизменение конструкции № 7), имевшей фурмы площадью, равной всего лишь $6,7 \%$ от площади сечения вагранки. В-третьих, видно, как легко посредством уменьшения сечения горна вагранки можно увеличить скорость дутья и интенсивность горения углерода кокса.

На фиг. 3 приведены характеристики, показывающие для различной высоты над фурмами изменение скоростей движения воздуха в фурмах и газов в вагранке (группа кривых $B$ ), а для различных видоизменений 
конструкции вагранок также время движения газов (группа кривых Б) и количество воздуха в процентах от общего воздуха (группа кривых $A$ ).

Часть кривых группы $B$ до высоты 150 мм над фурмами изображена пунктиром, так как она является предположительной. Некоторые авторы высказывают соображения, что живая сила воздуха теряется при встрече с первыми кусками кокса, однако наши наблюдения свидетельствуют о неправильности такого мнения. При систематических осмотрах после плавок внутренности вагранок с нашей системой фурм мы, как правило, об-

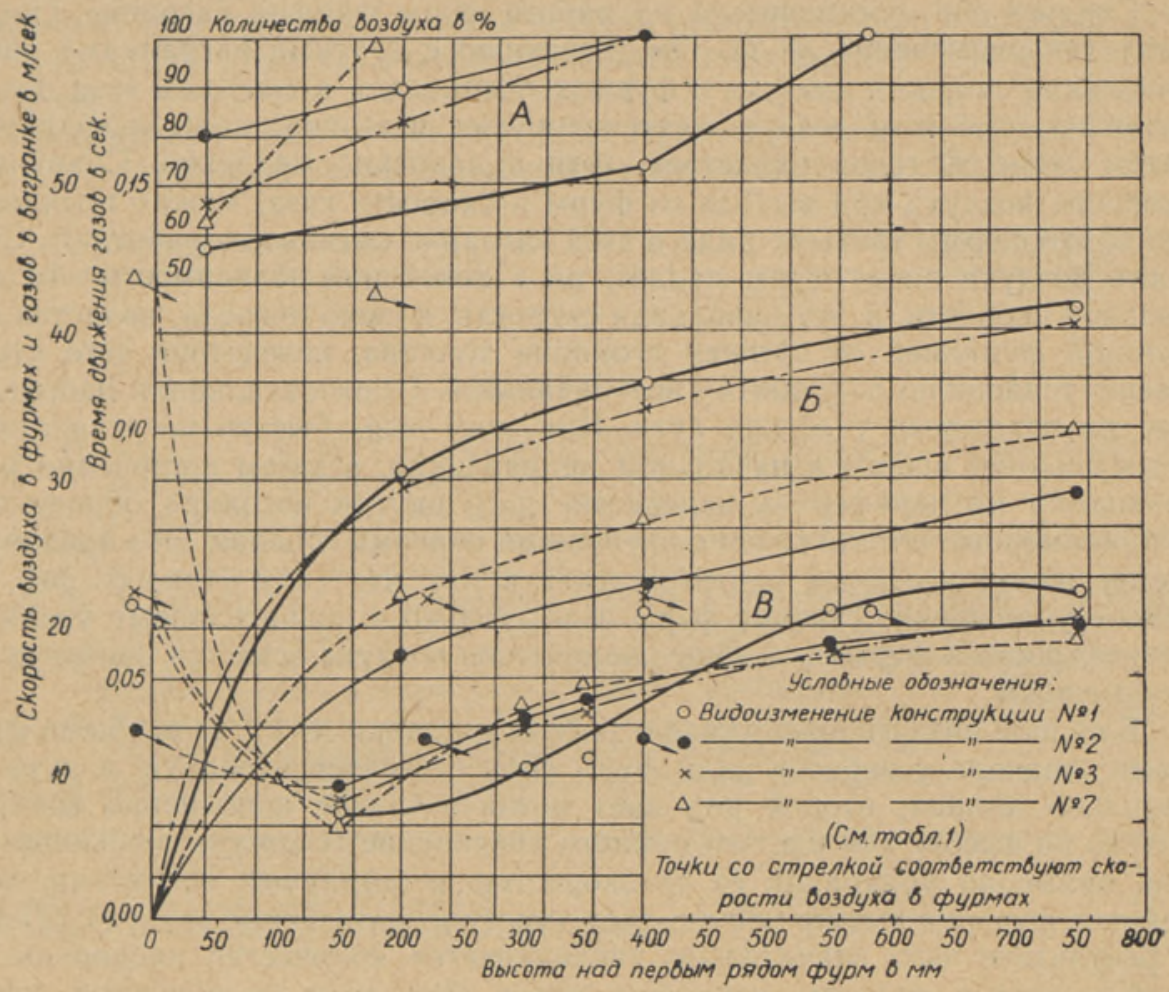

Фиг. 3.

наруживали на стенках, противоположных от фурм, по направлению основного потока дутья, разрушение футеровки в виде углублений, несколько приподнятых (примерно на $100-150$ мм) по отношению к уровню фурм.

Эти наблюдения позволяют считать, что концентрированные струи воздуха вследствие интенсивного выгорания кокса образуют каналы и тем самым прокладывают себе свободный путь по основному направлению потока. В наших опытах, в тех случаях, когда противоположные радиальные потоки не встречались, длина пути струй воздуха по горизонтали в основном направлении составляла от 0,5 до 0,7 м. Мы учли это обстоятельство при построении фиг. 3 , приняв в качестве средних значений при радиальных фурмах удлинение пути по горизонтали на 150 мм, а при отклоненных от радиуса фурмах - на 300 мм.

Фиг. 3 до некоторой степени подтверждает наше предположение, что на пути до высоты около 200 мм над фурмами скорости движения воздуха резко изменяются (кроме вагранки № 2, где перепад незначительный). Д,опустим, что живая сила струи теряется при встрече с коксом и что в 
дальнейшем скорости движения газов вверх являются только линейными функциями от температуры, как это изображено на фиг. 3. Тогда мы видим, что на высоте 150 мм от главных фурм наибольшее значение скорости газов (для видоизменения конструкции вагранки № 2) и наименьшее (для видоизменения № 7) отличаются друг от друга весьма незначительно: разница составляет всего около $3 \mathrm{~m} /$ сек, что не может оказать существенного влияния на процесс горения, хотя в действительности процессы сгорания различны.

Следует еще остановиться на работе фурм типовой вагранки Гипромеза (видоизменение № 2). По сравнению с другими вагранками здесь начальная скорость воздуха в фурмах очень мала и скорость газа незначительна, при этом воздух легко проникает в нижние зоны вагранки, а затем скорость газов нарастает, хотя и довольно медленно. Сравнивая скорости воздуха при выходе из фурм и скорости газа, можно предположить, что фурмы третьего ряда в этой вагранке активно не работают. Скорость воздуха после фурм падает, но с некоторой зависимостью от на, чальной скорости, а эта начальная скорость, в свою очередь, является некоторой функцией от степени сгорания топлива, вследствие чего струи имеют тенденцию сохранять свое начальное (горизонтальное) направление на, некоторых участках пути. При этом газы быстро нагреваются и устремляются вперед в начальном направлении, а затем постепенно рассеиваются на периферию, вследствие чего внутри вагранки образуются неравномерные потоки газов с активными очагами горения. Это предположение имеет некоторое подтверждение в том, что (как видно из фиг. 3) резкое уменьшение сечения фурм ведет только к значительному увеличению скорости в фурмах, а общее количество воздуха остается практически неизменным.

Большой интерес представляет работа вагранки № 1 с ее особыми фурмами; вначале у первого ряда фурм скорости газов невелики, а путь их довольно длинен; второй ряд дает незначительное пополнение воздуха только на высоте 400 мм, что немного увеличивает скорость движения газов, примерно уравнивая ее со скоростью в остальных вагранках; третий ряд фурм на высоте 580 мм дает заметное пополнение воздуха (27\%), в результате чего значительно увеличивается количество кислорода на этой высоте и скорость движения газов. При этом уменьшается время соприкосновения и реагирования $\mathrm{CO}_{2}$ с коксом, тормозится развитие эндотермического процесса восстановления $\mathrm{CO}_{2}$. Вагранка по своим показателям является весьма совершенной.

Вагранка завода «Пионер» (видоизменение конструкции № 7), работая с «острым» дутьем, имеет также неплохие показатели, но в ней все же сказывается отсутствие третьего ряда фурм, которые были бы весьма полезны на высоте 400 мм над уровнем нижнего ряда фурм.

\section{Выводы}

1. Типовые трехрядные вагранки с большой площадью сечения фурм не могут считаться достаточно совершенными и экономичными плавильными агрегатами.

Можно считать, что общепринятое отношение площади сечения фурм к сечению вагранки $(25 \%)$ не обосновано и вызывает увеличенный расход кокса вследствие нерационального его сжигания.

2. Для улучшения процесса горения и уменьшения расходғ кокса при плавке чугуна в вагранке является полезным значительное уменьшение 
площади первого ряда фурм и общей площади сечения фурм с целью получения «острого» дутья.

3. Уменьшению расхода кокса при плавке в вагранке способствует также уменьшение диаметра горна вагранки и отклонение осей фурм от радиуса горна вагранки в горизонтальной плоскости.

4. В дальнейшем желательно продолжить подобные исследования и дополнительно испытать фурмы с высокими узкими выходными сечениями и с осями, отклоненными так, чтобы встречные струи не препятствовали движению друг друга, особенно в нижних зонах вагранки, в которых длина пути струй воздуха в горизонтальном направлении имеет большое значение.

Проведенная нами реконструкция вагранок на трех небольших заводах дает ежегодную экономию кокса в количестве около 350 тонн.

Ннститут энергетики

Академии наук Эстонской ССР

Поступила в редакцию 29 XII 1953

\section{ЛИТЕРАТУРА}

1. П. П. Берг и Л. И. Серебри ер, Применение вагранок с несколькими рядами фурм, «Вестник машиностроения», № 3, 1950.

2. Н. Г. Ги р шо в и ч, Чугунное литье, Металлургиздат, Л.-М., 1949.

3. Н. Г. Г и ршови ч, О некоторых теоретических вопросах плавки чугуна в вагранках, «Литейное производство», № $1,1952$.

4. Л. М. М ар и е б ах, О правильном сечении дополнительных фурм в вагранках с распределенным дутьем, «Вестник машиностроения», № 12, 1944.

5. Л. М. М а р иенб ах и Ю. С. С у х а ч ук, Исследование механизма и кинетики горения топлива в вагранках, «Литейное производство», № 7, 1951.

6. Л. М. Мариенбах и Ю. С. Сух а рч ук, Методы интенсификации процесса горения в вагранках, «Литейное производство», № 2, 1952.

7. Л. Я. С адог урски й, Технологические резервы ваграночного процесса, Машгиз, М. 1950.

8. Ю. С. С ухар ч у К, М. К. 3 и льбе р и др. Современный ваграночный процесс, Машгиз, М., 1952.

9. Труды Гипромеза, вып. VIII, 1948.

10. Энциклопедический справочник машиностроения, т. 6, 1947. 